\title{
RESEARCH
}

Open Access

\section{Friedreich ataxia: metal dysmetabolism in dorsal root ganglia}

Arnulf H Koeppen ${ }^{1,2,3,4^{*}}$, Erik C Kuntzsch', Sarah T Bjork', R Liane Ramirez', Joseph E Mazurkiewicz ${ }^{5}$ and Paul J Feustel ${ }^{5}$

\begin{abstract}
Background: Friedreich ataxia (FA) causes distinctive lesions of dorsal root ganglia (DRG), including neuronal atrophy, satellite cell hyperplasia, and absorption of dying nerve cells into residual nodules. Two mechanisms may be involved: hypoplasia of DRG neurons from birth and superimposed iron (Fe)- and zinc (Zn)-mediated oxidative injury. This report presents a systematic analysis of DRG in 7 FA patients and 13 normal controls by X-ray fluorescence (XRF) of polyethylene glycol-embedded DRG; double-label confocal immunofluorescence microscopy of $\mathrm{Zn}$ - and Fe-related proteins; and immunohistochemistry of frataxin and the mitochondrial marker, ATP synthase F1 complex V $\beta$-polypeptide (ATP5B).
\end{abstract}

Results: XRF revealed normal total Zn- and Fe-levels in the neural tissue of DRG in FA (mean \pm standard deviation): $\mathrm{Zn}=5.46 \pm 2.29 \mu \mathrm{g} / \mathrm{ml}, \mathrm{Fe}=19.99 \pm 13.26 \mu \mathrm{g} / \mathrm{ml}$ in $\mathrm{FA} ; \mathrm{Zn}=8.16 \pm 6.19 \mu \mathrm{g} / \mathrm{ml}, \mathrm{Fe}=23.85 \pm 12.23 \mu \mathrm{g} / \mathrm{ml}$ in controls. Despite these unchanged total metal concentrations, Zn- and Fe-related proteins displayed major shifts in their cellular localization. The Zn transporter Zip14 that is normally expressed in DRG neurons and satellite cells became more prominent in hyperplastic satellite cells and residual nodules. Metallothionein 3 (MT3) stains confirmed reduction of neuronal size in FA, but MT3 expression remained low in hyperplastic satellite cells. In contrast, MT1/2 immunofluorescence was prominent in proliferating satellite cells. Neuronal ferritin immunofluorescence declined but remained strong in hyperplastic satellite cells and residual nodules. Satellite cells in FA showed a larger number of mitochondria expressing ATB5B. Frataxin immunohistochemistry in FA confirmed small neuronal sizes, irregular distribution of reaction product beneath the plasma membrane, and enhanced expression in hyperplastic satellite cells.

Conclusions: The pool of total cellular $\mathrm{Zn}$ in normal DRG equals $124.8 \mu \mathrm{M}$, which is much higher than needed for the proper function of Zn ion-dependent proteins. It is likely that any disturbance of Zn buffering by Zip14 and MT3 causes mitochondrial damage and cell death. In contrast to Zn, sequestration of $\mathrm{Fe}$ in hyperplastic satellite cells may represent a protective mechanism. The changes in the cellular localization of Zn- and Fe-handling proteins suggest metal transfer from degenerating DRG neurons to activated satellite cells and connect neuronal metal dysmetabolism with the pathogenesis of the DRG lesion in FA.

Keywords: Dorsal root ganglia, Ferritin, Friedreich ataxia, Iron, Metallothionein, X-ray fluorescence, Zinc, Zip14

\footnotetext{
* Correspondence: arnulf.koeppen@med.va.gov

${ }^{1}$ Research Services, Veterans Affairs Medical Center, 113 Holland Ave, Albany, NY 12208, USA

${ }^{2}$ Neurology Service, Veterans Affairs Medical Center, Albany, NY 12208, USA

Full list of author information is available at the end of the article
} 


\section{Background}

Dorsal root ganglia (DRG) are a primary target of Friedreich ataxia (FA) [1,2]. The reason for this vulnerability in comparison with other neural tissues is unknown. The mutation in the vast majority of patients with FA is a homozygous guanine-adenine-adenine (GAA) trinucleotide repeat expansion in intron 1 of the FXN gene that causes deficiency of frataxin, a small mitochondrial protein [3]. A critical effect of low frataxin levels is impaired function of iron (Fe)-sulfur cluster-dependent proteins [4]. Little disagreement exists that frataxin deficiency affects the function of mitochondrial complexes I, II, III, aconitase, and ferrochelatase, and that frataxin-depleted cultured cells are abnormally sensitive to reactive oxygen species. The role of $\mathrm{Fe}$ in this sensitivity to oxidative damage has been more controversial. Proponents and opponents have offered recent reviews of the evidence for Fe [5] or against Fe [6]. While assay of total Fe in DRG of FA patients did not show an increase above normal, prominent ferritin immunofluorescence in proliferating satellite cells suggested enhanced ferritin messenger RNA (mRNA) translation in response to local Fe excess [2]. The accumulation of ferritin in satellite cells surrounding dying DRG neurons, especially in the neuron-rich subcapsular region of DRG, matched Fe-specific signals on X-ray fluorescence (XRF) "maps" [2]. An upgraded version of the XRF unit allows the operator to quantify $\mathrm{Fe}$ and other metals in situ and to exclude DRG capsule, fat tissue, and adjacent spinal roots that often contain concretions of calcium (Ca), Fe, and $\mathrm{Zn}$. XRF technology recently established that the neural tissue of DRG contains substantial concentrations of $\mathrm{Zn}$. The importance of $\mathrm{Zn}$ in DRG arises from the fact that this transition metal is similar to Fe as a potential reactant in the synthesis of hydroxyl radicals through Fenton chemistry. This paper reports in-situ quantification of total $\mathrm{Zn}$ and $\mathrm{Fe}$, and changes in the metal-carrying proteins Zip14, metallothionein (MT) $1 / 2$ and 3, and ferritin in the DRG of FA. It also describes the frataxin deficit in DRG at the cellular level and the role of satellite cell hyperplasia in the pathogenesis of the DRG lesion in FA.

\section{Results}

\section{Autopsy specimens}

This work has received approval by the Institutional Review Board of the VA Medical Center, Albany, N.Y., USA. Table 1 lists basic clinical information on 7 FA patients from whom adequate DRG samples were available for XRF and matching slide preparations. All patients had homozygous GAA trinucleotide repeat expansions. The cause of death was hypertrophic cardiomyopathy in patients 2 and 4-7. Patients 1 and 3 died from cachexia in the course of their neurological disability. Normal control DRG tissue was available from 13 persons who died from non-neurological illnesses. Mean age \pm standard deviation (S.D.) was 62.5 \pm 9.1 years (range 48-77). Autopsy delay was $16.3 \pm 10.9 \mathrm{~h}$ in the FA cases (range $3-33$ ) and $22 \pm 20 \mathrm{~h}$ in the normal control subjects (range $1-56)$.

\section{Qualitative and quantitative XRF of $\mathrm{Zn}$ and $\mathrm{Fe}$}

Figure 1 illustrates the alignment of $\mathrm{Zn}$ - and Fe-XRF maps with matching sections respectively stained for class-III- $\beta$-tubulin, Zip14, and ferritin. Mean concentrations in $\mu \mathrm{g} / \mathrm{ml} \pm$ S.D. in 13 control subjects were $\mathrm{Zn}=8.16 \pm 6.19, \mathrm{Fe}=23.85 \pm 12.23$. In $7 \mathrm{FA}$ cases, they were $\mathrm{Zn}=5.46 \pm 2.29$ and $\mathrm{Fe}=19.99 \pm 13.26$. The average in each subject was used for a statistical comparison of metal concentrations by t-test which showed no difference between controls and FA. Figure 2 shows a linear regression analysis of $\mathrm{Zn}$ and Fe levels in all subjects. $\mathrm{Zn}$ and Fe levels are significantly correlated. Multiple linear regressions of control subjects and FA patients disclosed no significant differences of slope or intercept.

\section{Immunofluorescence and immunohistochemistry}

Figure 3 shows the localization of class-III- $\beta$-tubulin and Zip14 in DRG of a normal control and a case of FA by double-label immunofluorescence. In normal DRG, green class-III- $\beta$-tubulin immunofluorescence labels neurons, dendrites, and axons, while red Zip14 fluorescence of variable intensity arises from the cytoplasm of neurons and satellite cells. In FA, class-III- $\beta$-tubulinand Zip14-reactive nerve cells are much smaller, and Zip14 fluorescence is more prominent in multiple layers of satellite cells around atrophic neurons (Figure 3e). Figure 4 presents a comparison of Zip14 and ferritin immunofluorescence. These proteins show extensive colocalization in normal neurons and satellite cells though ferritin immunofluorescence is more intense than Zip14 immunofluorescence in satellite cells. In FA, Zip14- and ferritin-reactive nerve cells are smaller than normal, and the central portions of neurons appear depleted. Ferritin fluorescence arises prominently from multiple layers of satellite cells and a residual nodule (Figure 4e). Figure 5 displays the disparate localization of MT1/2 and MT3 in normal and FA DRG. MT1/2 immunofluorescence arises exclusively from satellite cells. The single perineuronal layer of MT1/2-positive satellite cells in normal DRG (Figure 5a) changes to multiple layers in FA (Figure 5d). In contrast, MT3 immunofluorescence is most prominent in neuronal cytoplasm of normal DRG though low-level emission also arises from satellite cells (Figure 5b). In FA, MT3 immunofluorescence identifies the cytoplasm of small DRG neurons but does not suggest greater expression in hyperplastic satellite cells (Figure 5e). 
Table 1 Basic clinical information on 7 patients with FA from whom suitable DRG tissue was available for XRF

\begin{tabular}{lllll}
\hline No. and sex & Age of onset & Age of death & Disease duration & GAA trinucleotide repeats \\
\hline $1 \mathrm{~F}$ & 5 & 25 & 20 & $1100 / 800$ \\
$2 \mathrm{M}$ & 7 & 34 & 27 & $1114 / 1114$ \\
$3 \mathrm{M}$ & 7 & 35 & 28 & $1000 / 750$ \\
$4 \mathrm{M}$ & 9 & 33 & 24 & $925 / 925$ \\
$5 \mathrm{M}$ & 10 & 24 & 14 & $1050 / 700$ \\
$6 \mathrm{~F}$ & 15 & 69 & 54 & $568 / 568$ \\
$7 \mathrm{~F}$ & 18 & 63 & 45 & $730 / 639$ \\
Mean \pm S.D.* & $10.1 \pm 4.7$ & $40.4 \pm 18.1$ & $30.3 \pm 14.2$ & $927 \pm 205 / 785 \pm 185$ \\
\hline
\end{tabular}

*S.D., standard deviation.

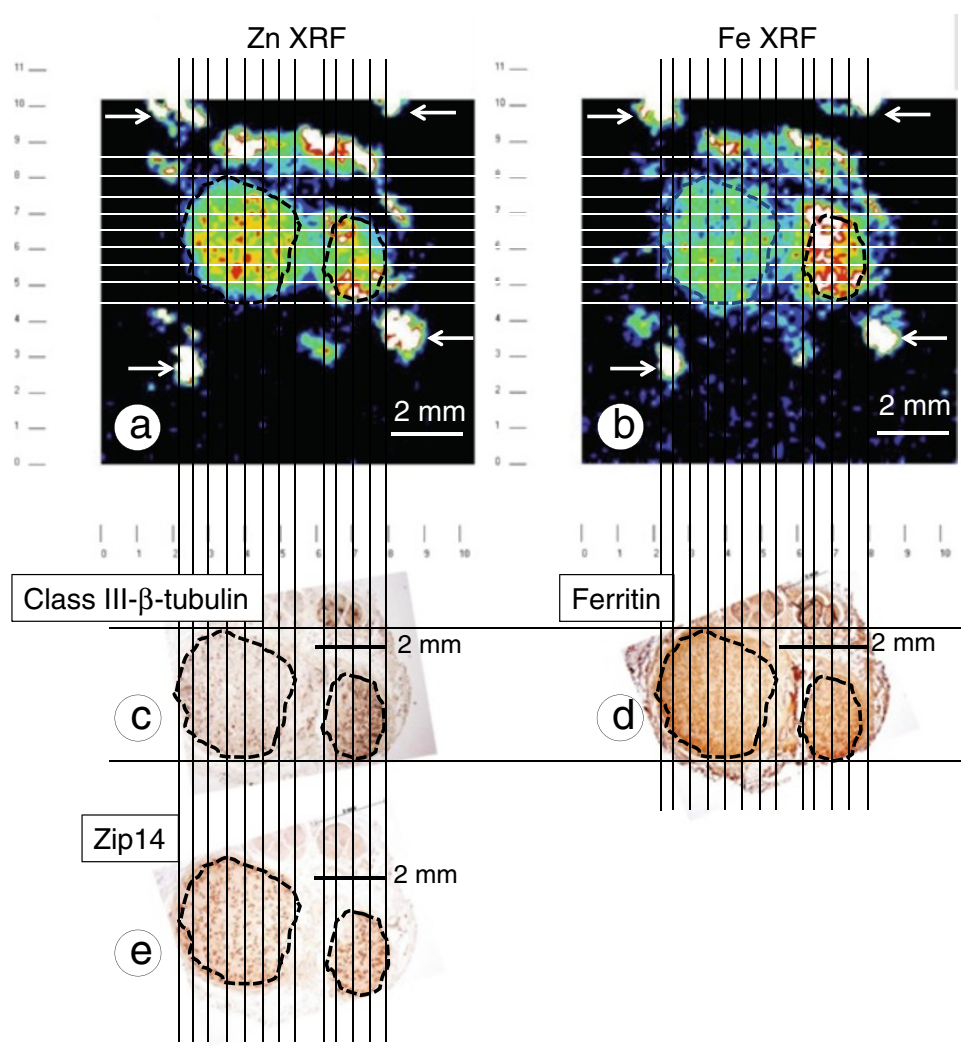

Figure 1 Alignment of $\mathrm{Zn}$ and Fe XRF maps of a DRG in FA and matching paraffin sections. (a), Zn XRF; (b), Fe XRF; (c) class-III- $\beta$-tubulin immunohistochemistry; (d), ferritin immunohistochemistry; (e), Zip14 immunohistochemistry. Low-power photographs of the stained sections were adjusted for size by reference to the $\mathrm{mm}$ scale on the XRF maps and rotated for optimal orientation. The illustrated DRG consisted of two portions of neural tissue that were identified by class-III- $\beta$-tubulin (c) and Zip14 reaction products (e). The region-of-interest containing the bulk of DRG neurons was outlined by interrupted lines. The outline was then transferred to the $\mathrm{Zn}$ and Fe XRF maps and the ferritin-stained section. Maps were segmented by vertical and horizontal lines placed at $0.5 \mathrm{~mm}$ intervals over the images to generate a grid. Within the maps, each square represented $0.25 \mathrm{~mm}^{2}$. At the edges, the squares were smaller. A single $\mathrm{Zn}$ or Fe signal was recorded as counts/10 sec from each square, and results of all signals were averaged for each metal. After subtracting background XRF, averaged counts were converted to $\mu \mathrm{g} Z \mathrm{n}$ or Fe per $\mathrm{ml} \mathrm{PEG} \mathrm{1450.} \mathrm{In} \mathrm{the} \mathrm{illustrated} \mathrm{case} \mathrm{of} \mathrm{FA,} Z \mathrm{n}=4.8 \mu \mathrm{g} / \mathrm{ml}$ and $\mathrm{Fe}=33.4 \mu \mathrm{g} / \mathrm{ml}$. The arrows in the two XRF maps indicate the location of Ti wires that are visible on the Zn and Fe XRF maps, respectively, due to minor contamination by these metals. Note strong Zn and Fe XRF arising from the capsule surrounding the neural portions of the DRG. These regions were effectively excluded from quantitative analysis by the illustrated alignment. Bars, $2 \mathrm{~mm}$. 


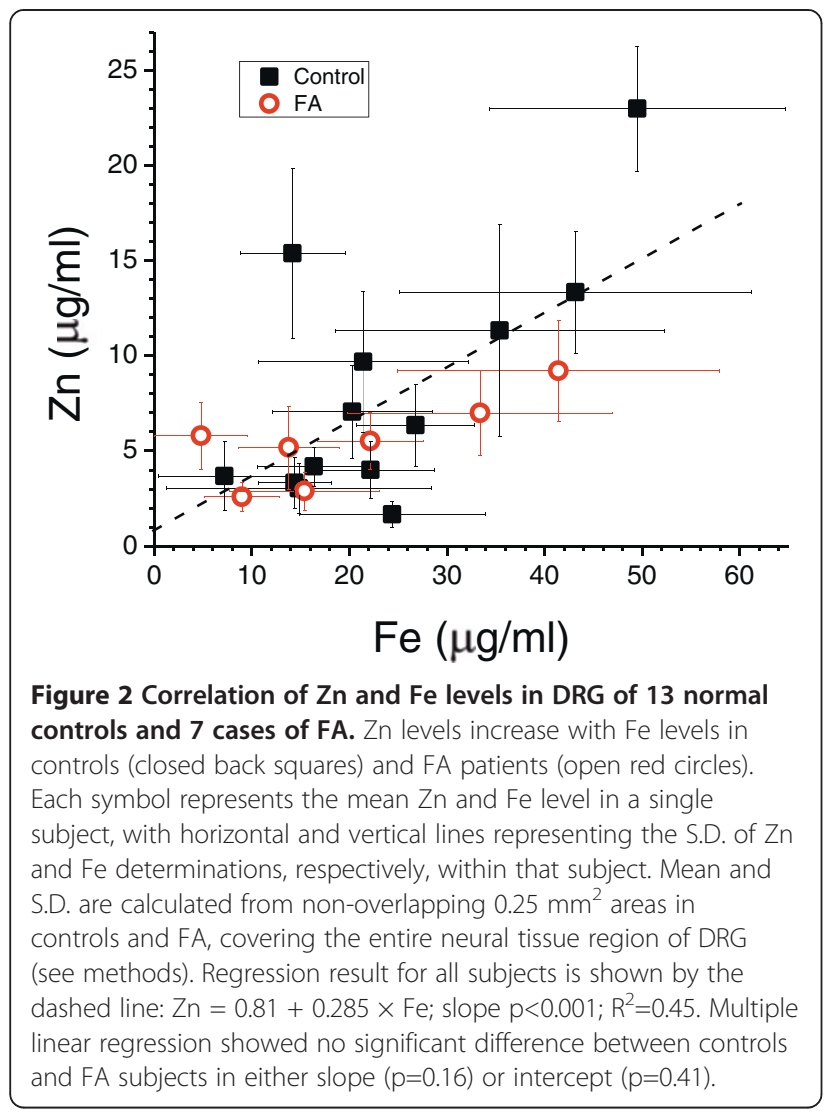

Figure 6 shows intense green immunofluorescence of S100 $\alpha$ in satellite cells (Figure 6a) and the great abundance of ATP synthase F1 complex V $\beta$-polypeptide (ATP5B)-positive mitochondria (red) in the cytoplasm of normal DRG neurons (Figure 6b). Very little ATP5B fluorescence is present in normal satellite cells (Figure 6b-c). In contrast, the S100 $\alpha$-positive hyperplastic satellite cells and residual nodule in FA display abundant, finely granular, red ATP5B fluorescence (Figure 6e-f).

Figure 7 shows a comparison of frataxin and ATP5B immunohistochemistry of a DRG in a normal control and a patient with FA. In the normal control, granular frataxin reaction product is present throughout the perikarya of all neurons, with very few reactive granules in satellite cells (Figure 7a). In FA, the antibody reveals smaller neurons, a paucity of granular reaction product in neuronal cytoplasm, and a greater abundance of positive granules in satellite cells (Figure 7d). Pre-absorption of the antibody with recombinant human frataxin eliminates the reaction (Figure $7 \mathrm{~b}$ and e). Incubation with an antibody to the mitochondrial marker ATP5B yields a very similar result: prominent granular staining of perikarya in normal DRG neurons (Figure 7c) and abundant reaction product in hyperplastic satellite cells in FA (Figure 7f).

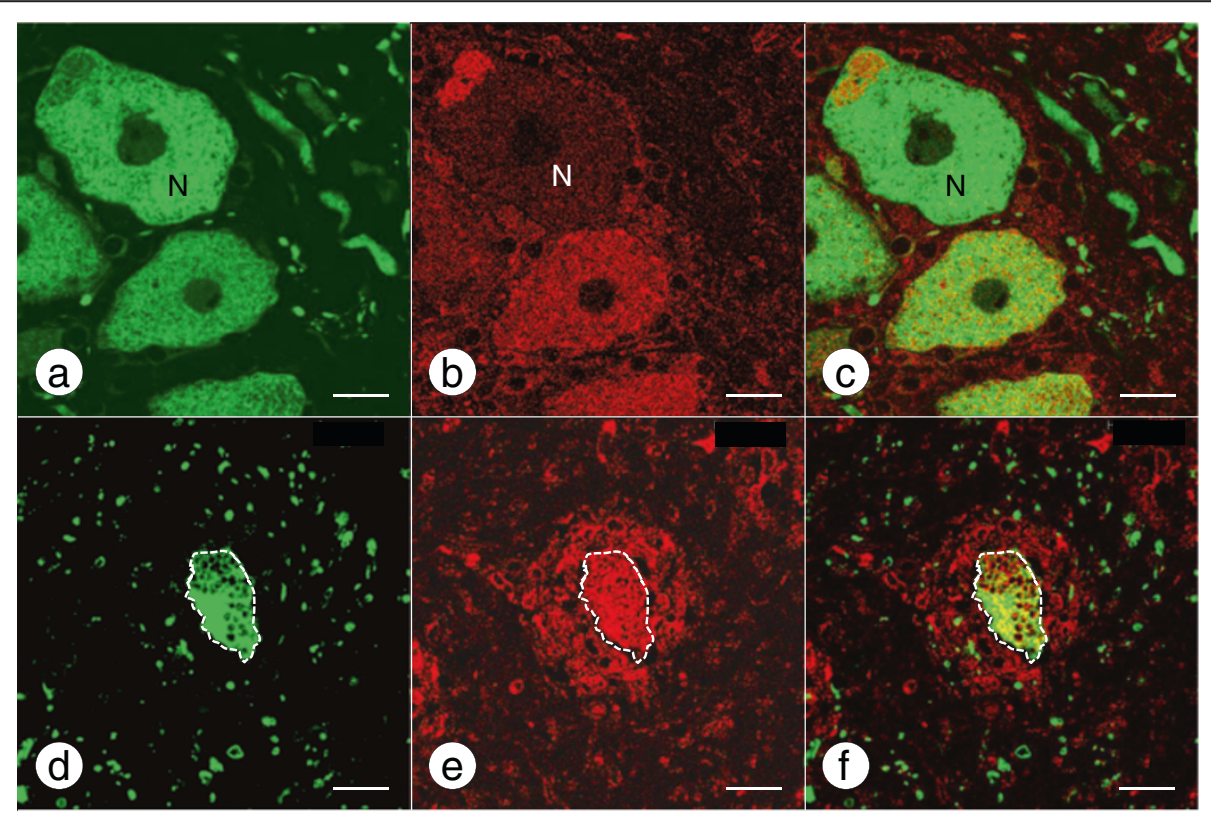

Figure 3 Double-label immunofluorescence of class-III- $\beta$-tubulin and Zip14 in a normal control DRG and a DRG of an FA patient. (a)-(c) normal control; (d)-(f) FA; (a) and (d) class-II- $\beta$-tubulin (Alexa488, green); (b) and (e) Zip14 (Cy3, red); (c) and (f) merged images. The normal DRG (a) shows large neurons that yield intense class-III- $\beta$-tubulin reaction product in perikaryon and dendrites. Zip14 staining (b) is heterogeneous, with less reaction product in the nerve cell marked by " $N$ ". Anti-Zip14 also visualizes satellite cells (b). In FA, a small class-III- $\beta$-tubulin-reactive neuron (d) continues to display Zip14 reaction product but is surrounded by multiple layers of Zip14-reactive satellite cells (e). Bars, $20 \mu \mathrm{m}$. 


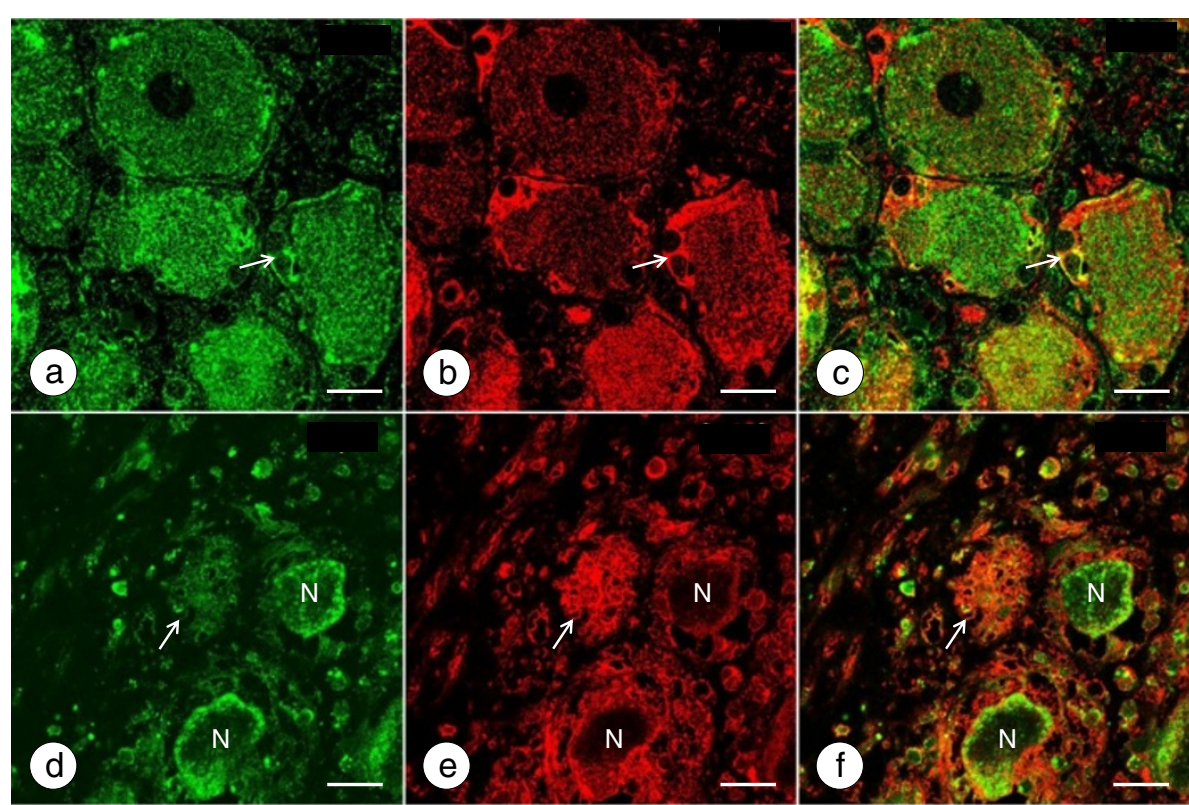

Figure 4 Double-label immunofluorescence of Zip14 and ferritin in a normal control DRG and a DRG of an FA patient. (a)-(c) normal control; (d)-(f) FA; (a) and (d) Zip14 (Alexa488, green); (b) and (e) ferritin (Cy3, red); (c) and (f) merged images. Zip14 (a) and ferritin reaction products (b) show co-localization in the cytoplasm of several large and small neurons and in perineuronal satellite cells (arrows). Zip14 and ferritin fluorescence in neurons is heterogeneous. In the FA case (d-f), neuronal Zip14 (d) and ferritin (e) have shifted to a location beneath the plasma membrane while the central portion of the nerve cells $(\mathrm{N})$ is devoid of reaction product. Zip14 fluorescence is present in satellite cells and a residual nodule (d, arrow). Ferritin fluorescence in multi-layer satellite cells and a residual nodule (e, arrow) is very prominent. Bars, $20 \mu \mathrm{m}$.
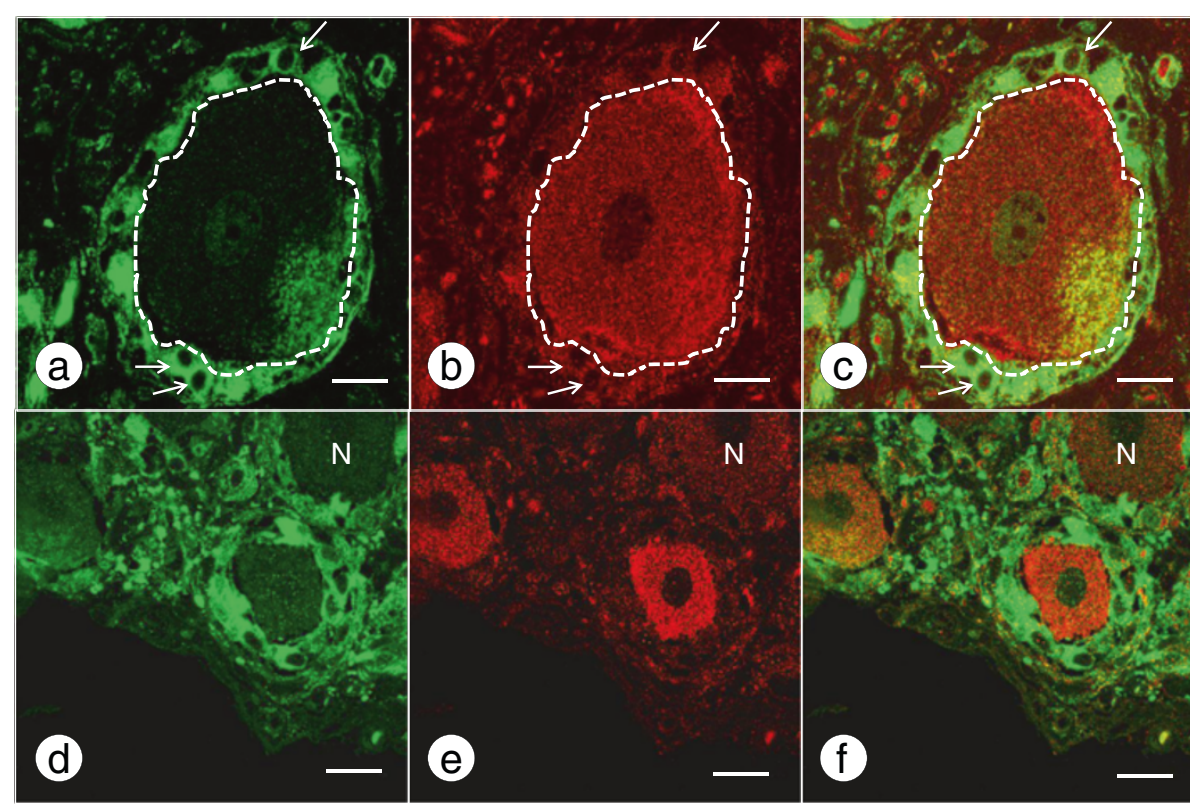

Figure 5 Double-label immunofluorescence of MT1/2 and MT3 in a normal control DRG and a DRG of an FA patient. (a)-(c) normal control; (d)-(f) FA; (a) and (d) MT1/2 (Alexa488, green); (b) and (e) MT3 (Cy3, red); (c) and (f) merged images. MT1/2 immunoreactivity is restricted to normal (a) and hyperplastic satellite cells in FA (d). MT3 immunofluorescence is localized in the cytoplasm of a normal large DRG neuron (b) and in satellite cells, in which it co-localizes with MT1/2 (a-c, arrows). In FA (e), one of three small DRG neurons shows very little MT3 immunofluorescence $(\mathrm{N})$ while two others remain strongly fluorescent. The thickened layers of satellite cells around the 3 neurons show relatively low MT3 fluorescence (e). Bars, $20 \mu \mathrm{m}$. 


\section{Discussion}

\section{Quantitative in-situ determination of $\mathrm{Zn}$ and Fe in DRG}

Systematic quantification of $\mathrm{Zn}$ in fresh or frozen autopsy specimens of normal DRG has not been reported. Total levels of Fe in DRG of FA patients and normal control subjects, however, are available [2]. Levels were $25.4 \pm 10.3 \mu \mathrm{g} / \mathrm{g}$ wet weight (mean \pm S.D.) in 3 samples from FA patients and $28 \pm 13.4 \mu \mathrm{g} / \mathrm{g}$ wet weight (mean \pm S.D.) in 8 normal controls. The difference was not significant. These results are now less applicable because the new method utilizing XRF can restrict measurements to neural tissues of DRG (Figure 1). While the relatively coarse steps $(0.15 \mathrm{~mm})$ of the scanning XRF instrument do not resolve the cellular localization of $\mathrm{Zn}$ or Fe, non-destructive XRF technology allows for intact tissue samples to be recovered, re-embedded in paraffin, sectioned, and stained for class-III- $\beta$-tubulin, Zip14, and ferritin. The critical step is matching XRF metal maps with stained tissue sections. Infiltration by PEG 1000 and PEG 1450 displaces all tissue water, and results expressed as $\mu \mathrm{g}$ metal/ml PEG 1450 (Figure 2) are equivalent to $\mu \mathrm{g}$ metal $/ \mathrm{ml}$ tissue volume. The results of $\mathrm{Zn}$ and Fe can be converted to $\mu \mathrm{g} / \mathrm{g}$ wet tissue weight by assuming DRG water content of at least 80 percent. When the mean XRF-recorded Fe levels in normal DRG $(23.85 \mu \mathrm{g} / \mathrm{ml}$ PEG) and DRG of FA $(19.99 \mu \mathrm{g} / \mathrm{m}$ PEG) are multiplied by 0.8 , the result yields $19.08 \mu \mathrm{g} / \mathrm{g}$ wet weight for controls, and $16 \mu \mathrm{g} / \mathrm{g}$ wet weight for FA. These concentrations are lower than the chemical assay of whole DRG [2], reflecting the exclusion of capsule and pericapsular tissues by XRF technology.

\section{Localization of $\mathrm{Zn}, \mathrm{Fe}$, and metal-related proteins in DRG}

The normal human DRG may be similar to rat DRG, in which Pérez-Castejón et al. [7] visualized Zn in the cytoplasm of neurons by histochemistry and autoradiography. Velázquez et al. [8] also detected the metal by fluorescence microscopy and MT3 by immunofluorescence in rat DRG. Autolysis due to delayed autopsy imposes severe limitations on the visualization of $\mathrm{Zn}$ by chemical and metallographic methods. None of the DRG specimens obtained from the FA patients listed in Table 1 were fixed within the optimal time limit of under $2 \mathrm{~h}[9,10]$. Therefore, this research utilized the immunodetection of Zip14, MT1/2, and MT3 as surrogate markers of $\mathrm{Zn}$, and ferritin as a marker of Fe. The intensity of Zip14 (Figures 3b and 4a) and MT3 immunofluorescence (Figure 5b) suggests that the bulk of $\mathrm{Zn}$ in normal DRG is located in the cytoplasm of neurons. In contrast to MT3, the more restrictive immunofluorescence of MT1/2 (Figure 5a and d) implies that this protein provides $\mathrm{Zn}$ homeostasis in normal (Figure 5a) and hyperplastic satellite cells (Figure 5d). While ferritin immunofluorescence is stronger in satellite cells than in neurons (Figure 4b), ferritin signal is also present in neurons where it co-localizes with Zip14 (Figure 4a).

\section{Supportive evidence of $\mathrm{Zn}$ and Fe translocation in FA}

The described observations establish that FA causes neither influx nor efflux of DRG Zn or Fe. Changes due to FA, however, are evident by immunofluorescence of several metal-handling proteins. The response of Zip14- and ferritin-immunoreactivity to FA is similar, suggesting the transition of $\mathrm{Zn}$ and Fe from degenerating neurons to satellite cells occurs by comparable mechanisms. It is likely that $\mathrm{MT} 1 / 2$ reacts to the transfer of $\mathrm{Zn}$ from neurons to satellite cells while MT3 remains restricted to smaller neurons (Figure 5e) and presumably disappears when atrophic nerve cells are totally absorbed into residual nodules.

Heretofore, MT3 was thought to be a unique central nervous system (CNS) protein [11], but its presence in DRG (Figure 5b) suggests that neuronal $\mathrm{Zn}$ homeostasis is similar.

In CNS, the most prominent $\mathrm{Zn}$ transporter is $\mathrm{ZnT3}$, which packages $\mathrm{Zn}$ into synaptic vesicles (review in ref [9]). As expected, an antibody to ZnT3 did not generate an immunohistochemical reaction in DRG, which under normal circumstances are devoid of synapses. Zip transporters, including Zip14, are not specific for $\mathrm{Zn}$, and it is noteworthy that the " $i$ " in Zip derives from "iron" [12,13]. Zip14 and MT3 may collaborate in Zn homeostasis of normal DRG neurons. While MT3 is a Zn storage and buffering protein, Zip14 adds $\mathrm{Zn}$ transport across plasma membranes. In some DRG neurons of FA, Zip14 immunofluorescence localizes to the cytoplasm just beneath the plasma membrane (Figure $4 \mathrm{~d}$ ). The transmembrane localization of functional $\mathrm{Zn}$ transporters may be relevant to this pathological phenomenon.

Origin and physiological role of $\mathrm{Zn}$ in normal human DRG are unknown. Velázquez et al. [8] reported that Zn in rat DRG may arise from retrograde axonal transport through dorsal spinal roots. It accumulated only in small-diameter DRG neurons, and the authors [8] considered a role in sensory processing. In humans with FA, loss of $\mathrm{Zn}$-containing DRG neurons may contribute to the complex pathological phenotype observed in dorsal roots [2] and sensory peripheral nerves [14].

\section{The role of satellite cells in FA}

The greater abundance of satellite cells in FA accounts for the hypercellularity of DRG that is readily apparent on routine cell stains [2]. It is likely that the earliest response to the disease is the formation of multiple layers of satellite cells about neurons. This phenomenon is especially apparent by ferritin (Figure 4e) and MT1/2 immunofluorescence (Figure 5d). Residual nodules 


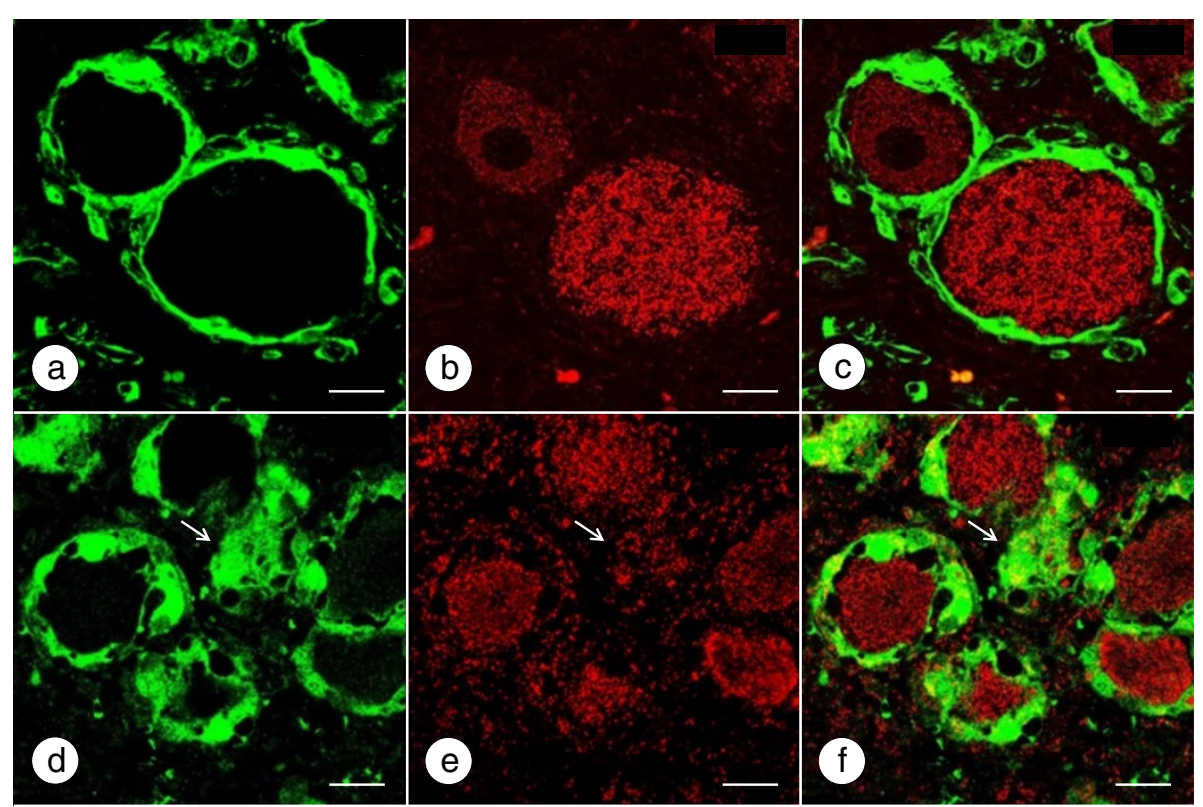

Figure 6 Double-label immunofluorescence of S100a and ATP5B in a normal control DRG and a DRG of an FA patient. (a)-(c) normal control; (d)-(f) FA; (a) and (d) S100a (Alexa488, green); (b) and (e) ATP5B (Cy3, red); (c) and (f) merged images. S100a immunofluorescence is a robust marker of normal satellite cells (a) and hyperplastic satellite cells in FA (d). In the normal DRG, ATP5B fluorescence is prominent in neuronal cytoplasm (b), and only sparse reaction product is present in the tissue between neurons. In contrast, satellite cells in FA (e) show a great abundance of granular ATP5B immunofluorescence. The arrows in $(\mathbf{d})-(\mathbf{f})$ indicate a residual nodule. Bars, $20 \mu \mathrm{m}$.

(Figure 4d-f) are a continuation of satellite cell hyperplasia beyond death of the neuron, but there is no insight yet about the fate of these cellular collections or whether they ultimately shed $\mathrm{Zn}$ and Fe into the blood stream.

In normal DRG, neuronal and satellite cell plasma membranes are very closely apposed, with multiple invaginations in both directions [15]. Also, satellite cells are tightly linked to each other. Beyond structural support, they handle "trafficking" into and out of DRG neurons. Pannese [15] also cited experimental studies, in which satellite cells provided "trophic support" to neurons. FA is typically a disease of nerve cells in the central

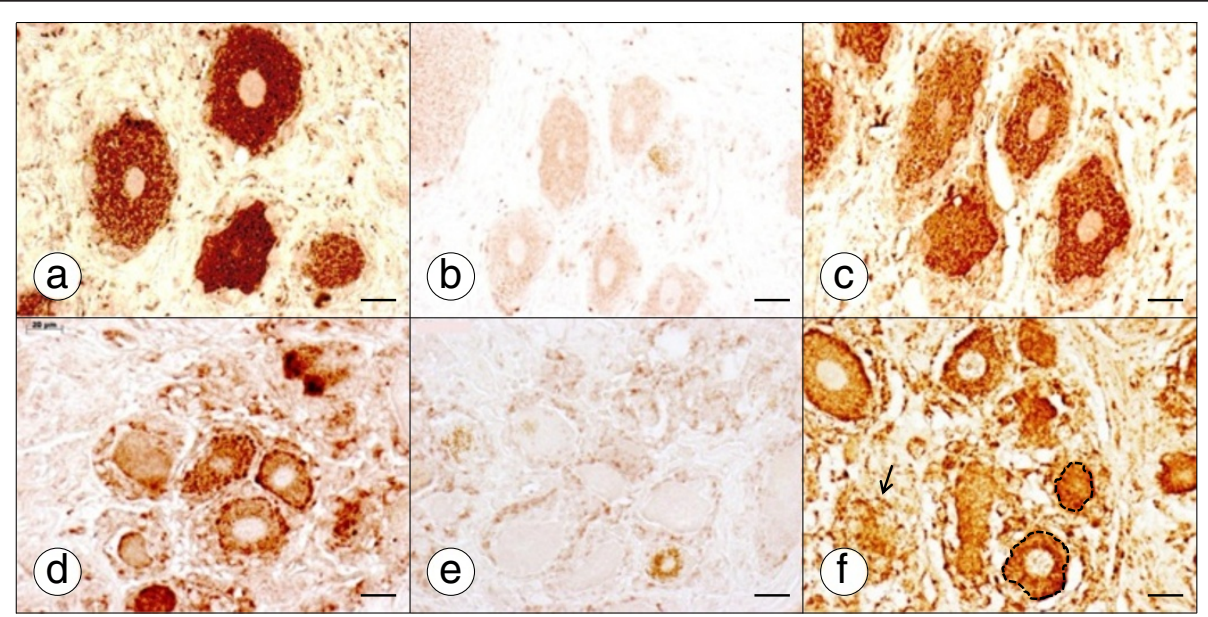

Figure 7 Frataxin and ATP5B immunohistochemistry of a normal control DRG and a DRG of an FA patient. (a)-(c) normal control; (d)-( $\mathbf{f}$ ) FA; (a) and (d) frataxin; (b) and (e) anti-frataxin antibody pre-absorbed by human recombinant frataxin; (c) and (f) ATP5B. In the normal DRG, granular frataxin reaction product fills the perikarya of all neurons (a). Reaction product in satellite cells is sparse. ATP5B immunohistochemistry yields a similar result (c). In FA (d-f), frataxin reaction product in small neurons is concentrated under the neuronal plasma membrane, and hyperplastic satellite cells display more frataxin-reactive granules than normal (d). In FA, ATP5B reaction product shows a distribution in neurons, hyperplastic satellite cells, and a residual nodule that resembles frataxin (f, arrow). Two neurons are outlined by interrupted lines. Bars, $20 \mu m$. 
nervous system (CNS) [1], and DRG neurons should therefore be similarly vulnerable to frataxin deficiency. It is a theoretical consideration that hyperplastic satellite cells, which also derive from the neural crest, do not adequately support their immediately adjacent neurons, and neuronal atrophy may be secondary.

The greater abundance of mitochondria in hyperplastic satellite cells and residual nodules in DRG of FA indicates that these cells develop a more active oxidative metabolism as part of the pathological phenotype (Figures 6e and 7f). In normal DRG, satellite cells contain few mitochondria (Figure $6 \mathrm{~b}-\mathrm{c}$ ) whereas reaction product of ATP5B is very abundant in the closely apposed neuron. In promptly fixed normal DRG, the available monoclonal anti-frataxin antibody shows reaction product that strongly resembles the distribution of the mitochondrial marker ATP5B (Figure 7). It is apparent that lack of frataxin does not impair the proliferation of satellite cells and the processing of the protein to its mature functional form [16].

\section{Endogenous metal toxicity or epiphenomenon?}

A key question in the pathogenesis of the DRG lesion in FA is: Do $\mathrm{Zn}$ and Fe in the cytosol of neurons become toxic, or is the shift in metal-related proteins an epiphenomenon of frataxin deficiency? Human autopsy tissues do not lend themselves to the direct measurement of toxic radicals, but changes in the cellular localization of Zip14, MT1/2, MT3, and ferritin suggest a disturbance is $\mathrm{Zn}$ and $\mathrm{Fe}$ homeostasis. In the absence of a synaptic source of $\mathrm{Zn}$, the mechanism of toxicity in DRG neurons may be similar to that in CNS neurons of ZnT3-deleted animals [17]. In the cytosol of CNS neurons, ionic $\mathrm{Zn}$ must be kept at picomolar or femtomolar levels to prevent toxicity and still meet metabolic demands [18]. It is likely that neurons in normal DRG maintain Zn homeostasis by buffering proteins such as MT3 (Figure $5 \mathrm{~b}$ ) and by sequestration of the metal in mitochondria [18]. The mean level of $8.16 \mu \mathrm{g} / \mathrm{ml}$ in normal DRG, reported in this study, is equal to a concentration of $124.8 \mu \mathrm{M}$. Neuronal toxicity is thought to occur at ionic $\mathrm{Zn}^{2+}$ levels in the range of $100 \mathrm{nM}$ to $3 \mu \mathrm{M}$ [18]. Therefore, the total pool of neuronal $\mathrm{Zn}$ in DRG is present in large excess over need, and control mechanisms must be very efficient. Dineley et al. $[19,20]$ summarized the evidence of endogenous $\mathrm{Zn}$ toxicity in the CNS, in which mitochondria bear the brunt of the damage. Mitochondrial impairment has many untoward effects: insufficient biosynthesis of adenosine triphosphate; decrease of mitochondrial membrane potential; release of cytochrome $\mathrm{C}$ and apoptosis-inducing factor; and generation of reactive oxygen species and nitric oxide [18]. All of these processes ultimately cause cell death. If they exist in FA in vivo, the untoward effects of $\mathrm{Zn}$ on DRG neurons are superimposed on deficient oxidative phosphorylation, which is a recognized effect of frataxin deficiency [4]. Fe in DRG may be less injurious than $\mathrm{Zn}$ because holoferritin has a prodigious ability to trap the metal. Therefore, the aggregation of $\mathrm{Fe}$ in the shell of ferritin in hyperplastic satellite cells may be protective against Femediated oxidative injury.

Based on experiments with frataxin-deleted mice [21], human neonates with homozygous mutations of the FXN gene must have at least some normal frataxin to survive to the mean age of death $(40 \pm 20$ years $[\mathrm{N}=30$; mean \pm S.D.]; ref. [22]). It is likely that DRG are hypoplastic at birth in all patients with mutated FXN genes $[1,2,23]$. A superimposed atrophic process may lead to progressive destruction of neurons, principally by satellite cell invasion and absorption into residual nodules. This transition may be the reason why clinical "onset" of FA is delayed to a mean age of 15 years [24]. It may be proposed that in DRG, $\mathrm{Zn}$ and Fe dysmetabolism contribute to onset and progression. In contrast to brain, however, nothing is known about the rate by which DRG acquire Zn and Fe during growth. Extrapolating from human brain, it is unlikely that end-point $\mathrm{Zn}$ accumulation in DRG coincides with onset of FA [25].

Many questions remain: Does frataxin deficiency trigger endogenous metal toxicity; and why do DRG in FA retain $\mathrm{Zn}$ and $\mathrm{Fe}$ rather than shedding the metals into the blood stream? The hypothesized accelerated DRG destruction by endogenous metals does not contradict other potential mechanisms of increasing disease activity, such as somatic GAA expansion in postmitotic neurons through the activity of mismatch repair enzymes [26] or greater epigenetic gene silencing [27].

\section{Conclusions}

The neural tissue of DRG contains measurable levels of $\mathrm{Zn}$ and Fe. During progressive destruction of DRG in FA, these metals are retained rather than discharged into the circulating blood. Enhanced expression of Zip14, MT1/2, and ferritin in hyperplastic satellite cells of DRG in FA represents indirect evidence that $\mathrm{Zn}$ and $\mathrm{Fe}$ are lost from degenerating neurons. Metabolic activation of satellite cells in FA is evident by the accumulation of ATP5B-expressing mitochondria. Failing metal homeostasis in DRG neurons may contribute to endogenous $\mathrm{Zn}$ toxicity whereas Fe sequestration in holoferritin of hyperplastic satellite cells may be neuroprotective.

\section{Methods}

\section{Polyethylene glycol embedding of specimens}

After fixation in buffered $4 \%$ formaldehyde solution for at least 10 days at $4^{\circ} \mathrm{C}$, DRG were divided into two portions. One portion was directly embedded in paraffin; the other portion was infiltrated by polyethylene glycol 
(PEG) 1450 as described before [28]. Tissue samples were immersed at room temperature in aqueous solutions of increasing concentrations (30-90\%) of PEG 400 (Sigma, St. Louis, MO, USA), followed by PEG 1000 and PEG 1450 at $60^{\circ} \mathrm{C}$. After cooling overnight, PEG 1450 blocks containing DRG tissues were trimmed and "faced" by microtome to present a smooth surface for scanning by XRF. Four segments of titanium (Ti) wire were inserted into the PEG blocks, a short distance from the tissue, to mark the scanning limits of the XRF instrument. Low level $\mathrm{Zn}$ and Fe contamination (0.01 percent) in the $\mathrm{Ti}$ wires generated $\mathrm{Zn}$ and Fe XRF that aided in the subsequent alignment of maps and tissue sections.

\section{XRF of PEG-embedded DRG and Zn and Fe standards}

The custom-built XRF machine consisted of a glassenclosed chamber housing a molybdenum target X-ray tube, X-ray optics with a doubly-curved crystal, an x-y coordinate scanning mechanism, and a silicon-drift detector [28]. Zn- and Fe-specific XRF was generated with a triple $\mathrm{X}$-ray beam over a period of $10 \mathrm{sec}$ per location with scanning steps of $0.15 \mathrm{~mm}$. The recorded XRF was converted to "maps" of Fe and Zn by the use of a Windows-based proprietary computer program. Pseudocolors indicated relative XRF intensities, with maximum fluorescence as white. Red, orange, green, and light blue represented progressively lower signal strengths. Fe and $\mathrm{Zn}$ calibration standards were prepared from Fe-III-mesoporphyrin and Zn-II-mesoporphyrin, respectively, and validated by elemental analysis as described before [28].

\section{Recovery of DRG from PEG 1450}

PEG-embedded DRG tissue was recovered by immersion in phosphate-buffered saline (PBS) and repeated washing in PBS at room temperature (RT). The tissue was postfixed for several hours at RT in buffered $4 \%$ formaldehyde solution ( $\mathrm{pH}$ 7.2) and embedded in paraffin by routine methods. Six- $\mu$ m-thick sections were stained by immunohistochemistry with antibodies to class-III- $\beta$-tubulin, Zip14, and ferritin as described below.

\section{Alignment of DRG sections with $\mathrm{Zn}$ and Fe maps, and quantitative measurement of $\mathrm{Zn}$ and $\mathrm{Fe}$}

Low-power photographs $(1.25 \times)$ of DRG sections stained for class-III- $\beta$-tubulin, Zip14, and ferritin were matched to the $\mathrm{Zn}$ and Fe XRF maps as shown in Figure 1. The neural tissue of the DRG was outlined based on class-III- $\beta$-tubulin and Zip14 reaction product. The limiting outline was transferred to the aligned $\mathrm{Zn}$ - and Fe-XRF maps to exclude signals arising from non-neural tissues, and to the ferritin-stained section. $\mathrm{Zn}$ and Fe maps were segmented in steps of $0.5 \mathrm{~mm}$ by the insertion of vertical and horizontal lines. Each square represented $0.25 \mathrm{~mm}^{2}$. Depending on the size of the available tissue sample, this method generated 21-111 squares for the 13 normal DRG and 12-64 squares for the 7 DRG of FA cases. Zn and Fe XRF in each square were recorded as counts/10 sec, and average and standard deviation (S.D.) were determined for each individual. An equal number of locations outside the region defined by the $\mathrm{Ti}$ wires were used to determine background XRF. After subtracting background XRF from the $\mathrm{Zn}$ - and Fe-signals, counts were converted to $\mu \mathrm{g} / \mathrm{ml}$ PEG by reference to calibration standards.

\section{Antisera, antibodies, antigen retrieval methods, immunohistochemistry, and immunofluorescence}

The following antisera (antibodies) were available for immunohistochemistry or immunofluorescence (host species, type of antibody, and commercial source in parentheses): ferritin (rabbit polyclonal, DAKO, Carpinteria, CA, USA; goat polyclonal, GenWay Biotech, San Diego, CA, USA); class-III- $\beta$-tubulin (mouse monoclonal antibody TUJ-1, R\&D Systems, Minneapolis, MN, USA); Zip14 (rabbit polyclonal, Novus Biological, Littleton, CO, USA); MT1/2 (mouse monoclonal, Invitrogen, Frederick, MD, USA); MT3 (rabbit polyclonal, Sigma-Aldrich, St. Louis, MO, USA); ATP5B (rabbit polyclonal, Santa Cruz Biotechnology, Santa Cruz, CA, USA); S100 $\alpha$ (mouse monoclonal, Santa Cruz); frataxin (mouse monoclonal, Mitosciences, Eugene, OR, USA). The MT isoforms 1 and 2 show extensive amino acid homology. The monoclonal antibody reacts with both proteins, hence, the designation "MT1/2". Optimal antibody dilutions were determined by trial and error, and protein concentrations ranged from $0.2-50 \mu \mathrm{g}$ protein $/ \mathrm{ml}$. Immunohistochemical and immunofluorescence protocols were described in detail in previous publications [2,23,28]. Antigen retrieval methods were DIVA (a proprietary decloaking solution marketed by Biocare Medical, Concord, CA, USA) for $30 \mathrm{~min}$ at $95^{\circ} \mathrm{C}$ for ferritin; incubation in $0.01 \mathrm{M}$ citric acid/sodium citrate buffer $(\mathrm{pH} 6)$ for $20 \mathrm{~min}$ at $95^{\circ} \mathrm{C}$ for class-III- $\beta$-tubulin, S100 $\alpha, \mathrm{MT} 1 / 2$, and MT3; and incubation in $0.1 \mathrm{M}$ tris buffer ( $\mathrm{pH} 9.5$ ) for $20 \mathrm{~min}$ at $95^{\circ} \mathrm{C}$ for $\mathrm{ATP} 5 \mathrm{~B}$ and frataxin. A chelating step with $2,2^{\prime}$-dipyridyl and sodium hydrosulfite $(30 \mathrm{mM}$ each in $0.1 \mathrm{M}$ acetic acid-sodium acetate buffer, $\mathrm{pH} 4.8$ ) was included for the visualization of ferritin and frataxin. The specificity of frataxin immunohistochemistry was confirmed by preincubation of the antibody solution with a 4fold excess of recombinant human frataxin (by concentration of protein). Biotinylated secondary antibodies came from Vector Labs (Burlingame, CA, USA). Sigma-Aldrich supplied horseradish peroxidase-labeled streptavidin. Paraffin sections were also used for double-label laser confocal scanning immunofluorescence microscopy of the pairs MT1/2/MT3; Zip14/class-III- $\beta$-tubulin; Zip14/ferritin; and S100 $\alpha$ /ATP5B. Fluorescently labeled donkey anti-rabbit and anti-mouse IgG antibodies (Alexa488 and Cy3) were 
purchased from Jackson ImmunoResearch (West Grove, PA, USA). The laser scanning confocal microscope was a Zeiss LSM 510 Meta unit. The exciting wavelengths for Alexa488 and Cy3 were 488 and 543 nm, respectively. Images were obtained at a magnification of $63 \times$ under oil immersion and through band pass filters of 500-530 nm for Alexa488 and 565-615 nm for Cy3.

\section{Abbreviations \\ ATP5B: ATP synthase F1 complex V $\beta$-polypeptide; CNS: Central nervous system; Cu: Copper; DRG: Dorsal root ganglion; FA: Friedreich ataxia; Fe: Iron; FXN: Frataxin gene; GAA: Guanine-adenine-adenine; MT: Metallothionein; PBS: Phosphate-buffered saline; PEG: Polyethylene glycol; RT: Room temperature; SD: Standard deviation; Ti: Titanium; XRF: X-ray fluorescence; Zn: Zinc.}

\section{Competing interests}

The authors declare that they have no competing interest.

\section{Authors' contribution}

AHK designed the study, drafted the manuscript, and assembled the illustrations. ECK, STB, and RLR provided the laboratory techniques, including PEG infiltration, XRF, tissue recovery from PEG, immunohistochemistry, and immunofluorescence. JEM contributed double-label laser scanning confocal immunofluorescence microscopy. PJF performed the statistical analysis of quantitative data and prepared Figure 2. All authors studied and revised the manuscript, and agreed on a final version prior to submission.

\section{Acknowledgments}

The authors express their sincere gratitude to the families who allowed the completion of autopsies for research in Friedreich ataxia. This work was supported by grants from National Institutes of Health (R01-NS069454), Bethesda, MD, USA; Friedreich's Ataxia Research Alliance, Downingtown, PA, USA; and National Ataxia Foundation, Minneapolis, MN, USA. Additional financial aid came from Neurochemical Research, Inc., Glenmont, N.Y., USA. The XRF unit was conceived and constructed by the staff of X-Ray Optical Systems, East Greenbush, N.Y., USA, with NIH grant support (5R44R022001). The described work was completed in the laboratories of the Veterans Affairs Medical Center in Albany, N.Y., USA. Dr. Grazia Isaya, Rochester, MN, USA, donated human recombinant frataxin. Dr. Karl Yang, Wadsworth Center, New York State Department of Health, Albany, N.Y., USA, provided the chemical validation of the $\mathrm{Zn}$ - and Fe-mesoporphyrin calibration standards.

\section{Author details}

${ }^{1}$ Research Services, Veterans Affairs Medical Center, 113 Holland Ave, Albany, NY 12208, USA. ${ }^{2}$ Neurology Service, Veterans Affairs Medical Center, Albany, NY 12208, USA. ${ }^{3}$ Department of Neurology, Albany Medical College, Albany, NY 12208, USA. ${ }^{4}$ Department of Pathology, Albany Medical College, Albany, NY 12208, USA. ${ }^{5}$ Center for Neuropharmacology and Neuroscience, Albany Medical College, Albany, NY 12208, USA.

Received: 15 June 2013 Accepted: 16 June 2013

Published: 19 June 2013

\section{References}

1. Koeppen AH, Mazurkiewicz JE: Friedreich ataxia: Neuropathology revised. J Neuropathol Exp Neurol 2013, 72:78-90.

2. Koeppen AH, Morral JA, Davis AN, Qian J, Petrocine SV, Knutson MD, Gibson WM, Cusack MJ, Li D: The dorsal root ganglion in Friedreich's ataxia. Acta Neuropathol 2009, 118:763-776.

3. Campuzano V, Montermini L, Moltò MD, Pianese L, Cossée M, Cavalcanti F, Monros E, Rodius F, Duclos F, Monticelli A, Zara F, Cañizares J, Koutnikova H, Bidichandani SI, Gellera C, Brice A, Trouillas P, De Michele G, Filla A, De Frutos R, Palau F, Patel PI, Di Donato S, Mandel JL, Cocozza S, Koenig M, Pandolfo M: Friedreich's ataxia: autosomal recessive disease caused by an intronic GAA triplet repeat expansion. Science 1996, 271:1423-1427.

4. Rötig A, De Lonlay P, Chretien D, Foury F, Koenig M, Sidi D, Munnich A, Rustin P: Aconitase and mitochondrial iron-sulphur protein deficiency in Friedreich ataxia. Nat Genet 1997, 17:215-217.
5. Armstrong JS, Khdour O, Hecht SM: Does oxidative stress contribute to the pathology of Friedreich's ataxia? A radical question. FASEB J 2010, 24:2152-2163.

6. Bayot A, Santos R, Camadro J-M, Rustin P: Friedreich's ataxia: the vicious circle hypothesis revisited. BMC Med 2011, 9:112.

7. Pérez-Castejón MC, Vera-Gil A, Lahoz M, Aisa J, Recreo MP, Pes N, Serrano P, Barral MJ: Location of zinc and ${ }^{65} \mathrm{Zn}$ in spinal ganglia of the rat. Histol Histopathol 2002, 17:799-803.

8. Velázquez RA, Cai Y, Shi Q, Larson AA: The distribution of zinc selenite and expression of metallothionein III mRNA in the spinal cord and dorsal root ganglia of the rat suggest a role for zinc in sensory transmission. J Neurosci 1999, 9:2288-2300.

9. Frederickson CJ, Koh J-Y, Bush Al: The neurobiology of zinc in health and disease. Nat Rev Neurosci 2005, 6:449-462.

10. Suh SW, Listiack K, Bell B, Chen J, Motamedi M, Silva D, Danscher G, Whetsell W, Thompson R, Frederickson C: Detection of pathological zinc accumulation in neurons: Methods for autopsy, biopsy, and cultured tissue. J Histochem Cytochem 1999, 47:969-972.

11. Hidalgo J, Aschner M, Zatta P, Vašák M: Roles of the metallothionein family of proteins in the central nervous system. Brain Res Bull 2001, 55:133-145.

12. Girijashanker $K$, He L, Soleiman M, Reed JM, Li H, Liu Z, Wang B, Dalton TP, Nebert DW: SIc39a14 gene encodes ZIP14, a metal/bicarbonate symporter: similarities to the ZIP8 transporter. Mol Pharmacol 2008, 73:1413-1423.

13. Lichten LA, Cousins RJ: Mammalian zinc transporters: Nutritional and physiological regulation. Annu Rev Nutr 2009, 29:153-176.

14. Morral JA, Davis AN, Qian J, Gelman BB, Koeppen AH: Pathology and pathogenesis of sensory neuropathy in Friedreich's ataxia. Acta Neuropathol 2010, 120:97-108.

15. Pannese E: The satellite cells of the sensory ganglia. Berlin: Springer; 1981.

16. Schmucker S, Argentini M, Carelle-Calmels N, Martelli A, Puccio H: The in vivo mitochondrial two-step maturation of human frataxin. Hum Mol Genet 2008, 17:3521-3531.

17. Lee YJ, Cole TB, Palmiter RD, Koh JY: Accumulation of $\mathbf{Z n}$ in degenerating hippocampal neurons of ZnT3-null mice after seizures: evidence against synaptic vesicle origin. J Neurosci 2000, 20(RC79):1-5.

18. Sensi SL, Paoletti P, Bush Al, Sekler I: Zinc in the physiology and pathology of the CNS. Nat Rev Neurosci 2009, 10:780-791.

19. Dineley KE, Votyakova TV, Reynolds IJ: Zinc inhibition of cellular energy production: implications for mitochondria and neurodegeneration. J Neurochem 2003, 85:563-570.

20. Dineley KE, Richards LL, Votyakova TV, Reynolds IJ: Zinc causes loss of membrane potential and elevates reactive oxygen species in rat brain mitochondria. Mitochondrion 2005, 5:55-65.

21. Cossée M, Puccio H, Gansmuller A, Koutnikova H, Dierich A, LeMeur M, Fischbeck K, Dollé $P$, Koenig M: Inactivation of the Friedreich ataxia mouse gene leads to early embryonic lethality without iron accumulation. Hum Mol Genet 2000, 9:1219-1226.

22. Koeppen AH: Friedreich's ataxia: Pathology, pathogenesis, and molecular genetics. J Neurol Sci 2011, 303:1-12.

23. Koeppen AH, Morral JA, McComb RD, Feustel PJ: The neuropathology of late-onset Friedreich's ataxia. Cerebellum 2011, 10:96-103.

24. Dürr A, Cossée M, Agid Y, Campuzano V, Mignard C, Penet C, Mandel J-L, Brice A, Koenig M: Clinical and genetic abnormalities in patients with Friedreich's ataxia. N Engl J Med 1996, 335:1169-1175.

25. Hu KH, Friede RL: Topographic determination of zinc in human brain by atomic absorption spectrophotometry. J Neurochem 1968, 15:677-685.

26. Bourn RL, De Biase I, Mouro Pinto R, Sandi C, Al-Mahdawi S, Pook MA, Bidichandani SI: Pms2 suppresses large expansions of the (GAA•TTC) sequence in neuronal tissues. PLoS One 2012, 7:e47085.

27. Sandi C, Al-Mahdawi S, Pook MA: Epigenetics in Friedreich's ataxia: Challenges and opportunities for therapy. Gen Res Int 2013, 201(3):852080.

28. Koeppen AH, Ramirez RL, Yu D, Collins SE, Qian J, Parsons PJ, Yang KX, Chen Z, Mazurkiewicz JE, Feustel PJ: Friedreich's ataxia causes redistribution of iron, copper, and zinc in the dentate nucleus. Cerebellum 2012, 11:845-860.

doi:10.1186/2051-5960-1-26

Cite this article as: Koeppen et al.: Friedreich ataxia: metal dysmetabolism in dorsal root ganglia. Acta Neuropathologica Communications 2013 1:26. 